\title{
Épocas e métodos de aplicação de nitrogênio em milho cultivado no sistema plantio direto
}

\author{
Timing and methods of nitrogen application for corn under no-tillage
}

\author{
Delmar Pöttker ${ }^{1}$ Sírio Wiethölter ${ }^{1}$
}

\section{RESUMO}

O milho (Zea mays L.), no sistema plantio direto, freqüentemente é cultivado após cereais de inverno. Durante a decomposição de resíduos culturais, pode ocorrer imobilização de nitrogênio $(N)$ e limitação do desenvolvimento da cultura. Visando avaliar métodos de manejo de $N$ sobre a produtividade de milho, cinco experimentos foram conduzidos, durante o período 1997 a 2002, sob sistema plantio direto. Aveia preta (Avena strigosa Schrieb) foi cultivada como cultura de cobertura precedendo o milho, tendo sido dessecada no estádio de antese. $O$ delineamento experimental dos experimentos foi blocos ao acaso, com quatro repetições e com número de tratamentos de 8 a 12. $O \mathrm{~N}$ foi aplicado em diferentes modos (na superfície, a lanço, e incorporado em linhas) e épocas (em pré-semeadura, na semeadura e na semeadura + cobertura), em dose única de $100 \mathrm{~kg} \mathrm{ha}^{-1}$, na forma de uréia. No primeiro ano de avaliação (1997/98), ocorreu elevada precipitação pluvial, observando-se rendimentos de grãos maiores nos tratamentos em que o $N$ foi aplicado na semeadura e cobertura, enquanto os demais tratamentos conferiram rendimentos inferiores e semelhantes entre si. Nas safras seguintes, com menor precipitação pluvial do que em 1997/98, não se observaram diferenças significativas entre os tratamentos com aplicação antecipada de $\mathrm{N}$ e naqueles com adubação em cobertura, exceto na safra 2000/2001, nos tratamentos com aplicação em pré-semeadura a lanço. Considerando o efeito médio dos tratamentos, observou-se que a aplicação de $N$ alguns dias após a dessecação de aveia preta, totalmente no momento da semeadura de milho, ou na semeadura e em cobertura são práticas viáveis no sistema plantio direto. A incorporação de $\mathrm{N}$ em relação à aplicação a lanço, tanto em pré-semeadura, na semeadura ou em cobertura, proporcionou, em média, acréscimos de $5 \%$ no rendimento de grãos de milho.

Palavras-chave: Zea mays, uréia, resíduos de aveia preta.

\section{ABSTRACT}

Corn (Zea mays L.) is usually cultivated after winter cereals under no-tillage in southern Brazil. During the decomposition of plant residues, nitrogen $(N)$ can be imobilized and limit plant growth. In order to evaluate the effect of timings and methods of $N$ application on corn yields, five experiments were carried out from 1997 to 2002, under no-tillage. Black oat (Avena strigosa Schrieb) was used as a preceding cover crop, beeing desiccated at anthesis. Randomized blocks were used as experimental design, with four replications, and 8 to 12 treatments. $N$ was applied to the soil by different methods (on the surface, broadcasted, and incorporated) and timing (before seeding, at seeding, and at seeding + topdressing), at the rate of $100 \mathrm{~kg} \mathrm{ha}^{-1}$, as urea. At the first year (1997/98), a very high amount of rain fell during the months of September and October, before and shortly after corn emergence. In this season, higher grain yield was obtained by the treatments with topdressed $N$ than by all other treatments, which were lower and similar among themselves. In the subsequent years, with less rainfall, no significant differences were observed among treatments, except in the 2000/2001 season, for the treatments in which $N$ was broadcasted before seeding. Considering the average yield, no differences were observed among the timings of $N$ application. On the average, incorporation of $N$, at any of the three timings of $N$ application, indicated a tendency to generate about $5 \%$ higher grain yields than soil surface application.

Key words: Zea mays, urea, residues of black oat.

\section{INTRODUÇÃO}

Para obter rendimentos elevados de milho (Zea mays L.), é necessário aplicar fertilizante nitrogenado, pois os solos, em geral, não suprem a demanda da cultura em termos de nitrogênio (N) nos diversos estádios de desenvolvimento da planta. A época de aplicação de $\mathrm{N}$ pode variar, sendo comum a aplicação, na semeadura, de parte do $\mathrm{N}$ recomendado, e o restante em cobertura, quando as plantas apresentam de 4 a 8 folhas (ESCOSTEGUY et al., 1997). Nos Estados do Rio Grande do Sul e de Santa Catarina, recomenda-se aplicar de 20 a $30 \mathrm{~kg} \mathrm{ha}^{-1} \mathrm{de}$

${ }^{1}$ Engenheiro Agrônomo, PhD., Pesquisador da Embrapa - Centro Nacional de Pesquisa de Trigo. In memoriam.

2Engenheiro Agrônomo, PhD., Pesquisador da Embrapa - Centro Nacional de Pesquisa de Trigo, CP 451, 99001-970, Passo Fundo, RS. E-mail: airiow@cnpt.embrapa.br. Autor para correspondência. 
$\mathrm{N}$ na semeadura, para cultivo sobre resíduos de gramíneas, e de 10 a $15 \mathrm{~kg} \mathrm{ha}^{-1}$ de $\mathrm{N}$ para cultivo sobre resíduos de leguminosas. O restante da dose é aplicada em cobertura, dependendo da expectativa de rendimento e do teor de matéria orgânica do solo (COMISSÃO ..., 1995).

A eficiência da aplicação de $\mathrm{N}$ previamente à semeadura do milho foi estudada por diversos autores (SÁ, 1996; DA ROS et al., 1999; PAULETTI \& COSTA, 2000; CERETTA et al., 2000). Todos verificaram pouca diferença entre as épocas de aplicação de N, mas CERETTA et al. (2000) alertaram que a aplicação antecipada à semeadura pode comprometer o rendimento de grãos em ano de elevada precipitação pluvial na fase inicial de desenvolvimento da cultura. Ao estudarem formas para manejar a aplicação de $\mathrm{N}$ em milho, encontraram que a produtividade diminuiu à medida que o $\mathrm{N}$, que seria aplicado em cobertura, foi aplicado no afilhamento da aveia preta cultivada antes do milho.

A aplicação de $\mathrm{N}$ em uma única época (em pré-semeadura ou na semeadura) pode resultar em acúmulo de $\mathrm{N}_{-} \mathrm{NO}_{3}^{-}$no solo nos estádios iniciais de desenvolvimento de milho (BASSO \& CERETTA, 2000), pois a demanda total da planta é pequena na fase inicial de desenvolvimento. Já no período usual de aplicação de $\mathrm{N}$ em cobertura (4 a 8 folhas) a absorção de $\mathrm{N}$ pelas plantas é mais intensa. A aplicação, antes ou no momento da semeadura, de todo o $\mathrm{N}$ recomendado para a cultura de milho, tem como principal objetivo aumentar a disponibilidade de $\mathrm{N}$ nos estádios iniciais de desenvolvimento da cultura e, assim, reduzir o efeito da imobilização de $\mathrm{N}$ pelos microrganismos do solo ao decomporem resíduos culturais de alta relação $\mathrm{C} / \mathrm{N}$. BASSO \& CERETTA (2000) verificaram, no decorrer do desenvolvimento da cultura, aumento do teor de nitrato no solo resultante da aplicação de fertilizante nitrogenado em pré-semeadura ou na semeadura.

$\mathrm{O} \mathrm{N}$ pode ser aplicado ao solo por diferentes métodos. Os mais usados são a aplicação a lanço na superfície do solo e a incorporação em linhas. Quando a fonte de $\mathrm{N}$ é uréia e não ocorrer chuva nos primeiros dias após a aplicação, a incorporação ao solo pode ser importante, pois pode ocorrer formação de amônia e sua liberação para a atmosfera. LARA CABEZAS et al. (2000) observaram maiores perdas de $\mathrm{NH}_{3}$ derivado da uréia quando ela foi aplicada na superfície do solo em comparação com a sua incorporação ao solo na cultura do milho. Os autores estimaram que pode haver redução no rendimento de grãos de milho devido à volatilização de $\mathrm{N}-\mathrm{NH}_{3}$, na proporção de $10 \mathrm{~kg} \mathrm{ha}^{-1}$ de grãos para cada $1 \%$ de $\mathrm{N}$ volatilizado.
Considerando que a sucessão aveia pretamilho é comum no sistema plantio direto e que, em geral, a produtividade de milho é altamente dependente do aporte de $\mathrm{N}$, objetivou-se determinar o efeito da aplicação de $\mathrm{N}$ a lanço ou incorporado ao solo, em pré-semeadura, semeadura e semeadura + cobertura, no rendimento de grãos de milho.

\section{MATERIAL E MÉTODOS}

Foram conduzidos cinco experimentos durante o período 1997 a 2002, em área do Centro Nacional de Pesquisa de Trigo, Passo Fundo, RS. O solo das áreas experimentais é classificado como Latossolo Vermelho Distrófico típico (EMBRAPA, 1999), com teor de matéria orgânica variando de 36 a $40 \mathrm{~g} \mathrm{dm}^{-3}$ na profundidade de 0 a $20 \mathrm{~cm}$. Os experimentos foram conduzidos em cinco locais diferentes, usando-se o delineamento de blocos ao acaso e quatro repetições, sendo composto por 8 tratamentos em 1997/98, 9 em 1998/99 e 12 nos anos seguintes. Os tratamentos foram arranjados no esquema fatorial (épocas vs modos de aplicação de $\mathrm{N})$. A cultura de cobertura de solo no inverno foi aveia preta, sendo adubada com $45 \mathrm{~kg} \mathrm{ha}^{-1}$ de $\mathrm{N}$, na forma de uréia. Os tratamentos incluíram aplicações de $\mathrm{N}$ antes da semeadura (geralmente 10 dias após a dessecação da aveia), aplicações na semeadura e na semeadura + cobertura (Tabela 1). Alguns tratamentos envolveram aplicação a lanço na superfície, e outros, incorporação na linha de semeadura. Em todos os tratamentos, exceto na testemunha, aplicaram-se $100 \mathrm{~kg} \mathrm{ha}^{-1} \mathrm{de} \mathrm{N}$, na forma de uréia.

A semeadura foi realizada com semeadora de parcelas equipada com duas linhas de semeadura. A dimensão das parcelas foi $10 \mathrm{~m}$ de comprimento e $5,4 \mathrm{~m}$ de largura (seis fileiras espaçadas de $0,9 \mathrm{~m}$ ). Visando obter população uniforme de plantas, realizou-se desbaste para 55.000 plantas $\mathrm{ha}^{-1}$. As datas das principais operações realizadas no campo, assim como os híbridos de milho utilizados, constam na tabela 1 , na qual se verifica que as semeaduras foram realizadas em setembro e outubro e as colheitas em março e abril.

No estádio de maturação dos grãos, foram colhidas as duas fileiras centrais de cada parcela. Os grãos foram secados e pesados, sendo o rendimento ajustado para umidade nos grãos de $130 \mathrm{~g} \mathrm{~kg}^{-1}$. A análise estatística foi realizada empregando-se o programa SAS (1993), tendo as médias sido comparadas pelo teste de Duncan ao nível de $5 \%$ de probabilidade de erro. 
Tabela 1 - Datas de realização das principais práticas de campo e híbridos de milho usados nos experimentos. Embrapa Trigo, Passo Fundo, RS

\begin{tabular}{lcccccccc}
\hline No Exp. & Safra & $\begin{array}{c}\text { Dessecação de } \\
\text { aveia-preta }\end{array}$ & $\begin{array}{c}\text { Aplicação de N em } \\
\text { pré-semeadura }\end{array}$ & $\begin{array}{c}\text { Semeadura de } \\
\text { milho }\end{array}$ & $\begin{array}{c}\text { Desbaste de } \\
\text { milho }\end{array}$ & $\begin{array}{c}\text { Adubação } \\
\text { em cobertura }\end{array}$ & $\begin{array}{c}\text { Colheita } \\
\text { Híbrido de } \\
\text { milho }\end{array}$ \\
\hline 1 & $1997 / 1998$ & $30 / 08 / 1997$ & $08 / 09 / 1997$ & $18 / 09 / 1997$ & $30 / 10 / 1997$ & $07 / 11 / 1997$ & $12 / 3 / 1998$ & XL-203 \\
2 & $1998 / 1999$ & $10 / 09 / 1998$ & $01 / 10 / 1998$ & $08 / 10 / 1998$ & $11 / 11 / 1998$ & $17 / 11 / 1998$ & $15 / 3 / 1999$ & XL-212 \\
3 & $1999 / 2000$ & $23 / 09 / 1999$ & $06 / 10 / 1999$ & $21 / 10 / 1999$ & $29 / 11 / 1999$ & $03 / 12 / 1999$ & $24 / 4 / 2000$ & XL-344 \\
4 & $2000 / 2001$ & $20 / 09 / 2000$ & $29 / 09 / 2000$ & $09 / 10 / 2000$ & $18 / 11 / 2000$ & $24 / 11 / 2000$ & $02 / 4 / 2001$ & XL-212 \\
5 & $2001 / 2002$ & $25 / 09 / 2001$ & $11 / 10 / 2001$ & $19 / 10 / 2001$ & $27 / 11 / 2001$ & $28 / 11 / 2001$ & $10 / 4 / 2002$ & DKB-747 \\
\hline
\end{tabular}

\section{RESULTADOS E DISCUSSÃO}

\section{Produção de matéria seca de aveia preta}

$\mathrm{Na}$ tabela 2, constam os dados de rendimento de matéria seca (MS) de aveia preta e seu teor de N. Verificou-se que a produção mais elevada $\left(4,7 \mathrm{t} \mathrm{ha}^{-1}\right)$ foi obtida no ano de 2000. Na média dos anos, a produção ficou ao redor de $3,5 \mathrm{tha}^{-1}$. Não houve relação entre o rendimento médio de milho de dois tratamentos com $\mathrm{N}$ antecipado (tratamentos $3 \mathrm{e} 4 \mathrm{da}$ Tabela 3) e a quantidade de MS produzida pela aveia preta, pois a resposta média ao $\mathrm{N}$ aplicado, em relação à testemunha, nesses tratamentos foi de 35; 55; $48 \mathrm{e}$ $15 \%$, respectivamente, nos anos de 1998/99, 1999/00, 2000/01 e 2001/02. A MS produzida pela aveia preta também não se relacionou com a resposta ao $\mathrm{N}$ nos tratamentos com adubação em cobertura (tratamentos 11 e 12 da Tabela 3), onde a resposta média foi de 37, 59,53 e $17 \%$, respectivamente, nos mesmos anos. Dessa forma, o rendimento médio de grãos, em cada safra, foi mais afetado pelas condições climáticas do que pela MS produzida pela aveia preta.

\section{Épocas de aplicação de $\mathbf{N}$}

Os dados de rendimento de grãos de milho são apresentados na tabela 3 , na qual se constata que, com exceção dos anos agrícolas 1997/98 e 2000/01, não ocorreram diferenças significativas entre os tratamentos com aplicação antecipada de $\mathrm{N}$ e aqueles com adubação em cobertura.

Conforme indicado na tabela 4, em 1997/

98 ocorreu elevada precipitação nos meses de outubro e novembro (ano de ocorrência do evento meteorológico El Niño), tendo o maior rendimento de grãos de milho sido obtido nos dois tratamentos que receberam adubação em cobertura, enquanto todos os demais tratamentos apresentaram rendimentos estatisticamente inferiores e semelhantes entre si. Como não ocorreu déficit hídrico em todo o período de cultivo do milho, os resultados obtidos podem ser atribuídos à disponibilidade de N, proporcionada pelos diversos tratamentos, conforme relatam BASSO \& CERETTA (2000) e MUZILLI \& OLIVEIRA (1982). Devido à elevada precipitação em outubro e novembro, é provável que perdas de $\mathrm{N}$ ocorreram, pelo processo de lixiviação de nitrato (BASSO \& CERETTA, 2000) ou por denitrificação (TORBERT et al., 1993), nos tratamentos com $\mathrm{N}$ aplicado em présemeadura e na semeadura. Segundo BORTOLINI et al. (2001), o excesso de chuva (ou de irrigação) é prejudicial ao milho, principalmente quando a aplicação de $\mathrm{N}$ é antecipada para o período de présemeadura. No experimento, verificou-se que a precipitação pluvial entre a semeadura do milho e a data da adubação de cobertura, foi muito elevada $(843,4 \mathrm{~mm})$. Por isso, a aplicação de $\mathrm{N}$ na semeadura e em cobertura (método padrão) ocasionou acréscimo médio de $28 \%$ no rendimento de grãos de milho, em relação à média dos outros tratamentos.

No ano agrícola 1998/99 (ano de ocorrência do evento meteorológico La Niña), todos os tratamentos que receberam $\mathrm{N}$ apresentaram rendimento de grãos semelhante, diferindo apenas da testemunha (sem N). No ano agrícola 1999/00, também de precipitação pluvial abaixo da normal nos primeiros 60 dias da cultura, todos os tratamentos apresentaram rendimento similar, exceto os tratamentos 1 e $7 . \mathrm{Na}$

Tabela 2 - Matéria seca (M. S.) e teor de $\mathrm{N}$ da aveia preta utilizada no experimento e quantidade de $\mathrm{N}$ na matéria seca, antes da dessecação. Embrapa Trigo, Passo Fundo, RS

\begin{tabular}{lccc}
\hline Ano & M S & Teor de N & N na planta \\
\hline & $\mathrm{kg} \mathrm{ha}^{-1}$ & $\mathrm{~g} \mathrm{~kg}^{-1}$ & $\mathrm{~kg} \mathrm{ha}^{-1}$ \\
1997 & 3.280 & 17,5 & 57 \\
1998 & 2.950 & 21,6 & 64 \\
1999 & 3.065 & 22,2 & 68 \\
2000 & 4.773 & 20,5 & 98 \\
2001 & 3.646 & 15,8 & 58 \\
Média & 3.543 & 19,5 & 69 \\
\hline
\end{tabular}

Ciência Rural, v. 34, n.4, jul-ago, 2004. 
Tabela 3 - Efeito de época e método de aplicação de N no rendimento de grãos de milho cultivado sobre resíduos de aveia-preta. Embrapa Trigo, Passo Fundo, RS, 1997-2002.

\begin{tabular}{|c|c|c|c|c|c|c|c|c|c|}
\hline \multirow{2}{*}{$\mathrm{N}^{\mathrm{o}}$ Trat. } & \multicolumn{3}{|c|}{ Época e método de aplicação de $\mathrm{N}$} & \multicolumn{5}{|c|}{ Safras } & \multirow[t]{2}{*}{ Média } \\
\hline & $\begin{array}{c}\text { Pré- } \\
\text { semeadura }^{1}\end{array}$ & Plantio & Cobertura & $0 \quad 1997 / 1998^{2}$ & $1998 / 1999^{3}$ & $1999 / 2000$ & $2000 / 2001$ & $2001 / 2002$ & \\
\hline & \multicolumn{3}{|c|}{------------ kg N ha' ${ }^{-1}$} & \multicolumn{6}{|c|}{ 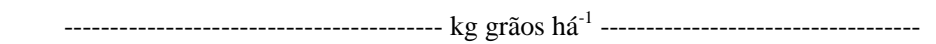 } \\
\hline 1 & 0 & 0 & 0 & - & $6.556 \mathrm{~b}$ & $4.736 \mathrm{c}$ & $6.417 \mathrm{e}$ & $5.843 \mathrm{~d}$ & 5.888 \\
\hline 2 & $\begin{array}{c}100 \\
\text { Lanço }^{4}\end{array}$ & 0 & 0 & - & - & $7.407 \mathrm{ab}$ & - & - & 7.407 \\
\hline 3 & 100 Lanço & 0 & 0 & $6.404 \mathrm{bc}$ & $8.604 \mathrm{a}$ & $7.320 \mathrm{ab}$ & $9.078 \mathrm{~d}$ & $6.502 \mathrm{c}$ & 7.582 \\
\hline 4 & 100 Linha $^{5}$ & 0 & 0 & $6.897 \mathrm{~b}$ & $9.148 \mathrm{a}$ & $7.383 \mathrm{ab}$ & $9.937 \mathrm{abc}$ & $6.940 \mathrm{abc}$ & 8.061 \\
\hline $5^{6}$ & 70 Lanço & 30 Linha & 0 & $6.170 \mathrm{c}$ & $9.087 \mathrm{a}$ & $7.464 \mathrm{a}$ & $9.128 \mathrm{~cd}$ & $7.105 \mathrm{ab}$ & 7.791 \\
\hline $6^{6}$ & 70 Linha & 30 Linha & 0 & $6.653 \mathrm{bc}$ & $9.313 \mathrm{a}$ & $7.708 \mathrm{a}$ & $10.240 \mathrm{a}$ & $7.306 \mathrm{a}$ & 8.244 \\
\hline 7 & 30 Lanço & 70 Lanço & 0 & - & - & $6.742 \mathrm{~b}$ & $9.270 \mathrm{bcd}$ & $6.573 \mathrm{bc}$ & 7.528 \\
\hline 8 & 30 Lanço & 70 Linha & 0 & - & - & - & $9.580 \mathrm{bcd}$ & $6.993 \mathrm{abc}$ & 8.286 \\
\hline 9 & 30 Lanço & 30 Linha & $\begin{array}{c}40 \\
\text { Lanço }\end{array}$ & - & - & $7.296 \mathrm{ab}$ & $9.997 \mathrm{ab}$ & $7.201 \mathrm{a}$ & 8.165 \\
\hline 10 & 30 Lanço & 0 & $\begin{array}{c}70 \\
\text { Lanço }\end{array}$ & - & - & $7.316 \mathrm{ab}$ & $9.253 \mathrm{bcd}$ & $6.954 \mathrm{abc}$ & 7.841 \\
\hline $11^{7}$ & 0 & 30 Linha & $\begin{array}{c}70 \\
\text { Lanço }\end{array}$ & $8.128 \mathrm{a}$ & $8.880 \mathrm{a}$ & $7.872 \mathrm{a}$ & $9.619 \mathrm{abcd}$ & $6.692 \mathrm{bc}$ & 8.238 \\
\hline $12^{7}$ & 0 & 30 Linha & 70 Linha & $8.534 \mathrm{a}$ & $9.133 \mathrm{a}$ & $7.192 \mathrm{ab}$ & $9.972 \mathrm{ab}$ & $6.974 \mathrm{abc}$ & 8.361 \\
\hline 13 & 0 & 100 Lanço & 0 & $6.538 \mathrm{bc}$ & $9.106 \mathrm{a}$ & - & $8.914 \mathrm{~d}$ & $6.775 \mathrm{abc}$ & 7.833 \\
\hline \multirow[t]{4}{*}{14} & 0 & $70^{8}+30$ Linha & 0 & $6.354 \mathrm{bc}$ & $9.260 \mathrm{a}$ & $7.398 \mathrm{ab}$ & - & - & 7.671 \\
\hline & \multicolumn{3}{|c|}{ Média } & 6.960 & 8.787 & 7.153 & 9.284 & 6.822 & 7.801 \\
\hline & \multicolumn{3}{|c|}{ DMS } & 793 & 941 & 833 & 852 & 613 & - \\
\hline & \multicolumn{3}{|c|}{$\mathrm{CV} \%$} & 6,8 & 6,4 & 6,9 & 5,4 & 5,3 & - \\
\hline
\end{tabular}

${ }^{1}$ Após a dessecação da aveia.

${ }^{2}$ Ocorrência do evento metereológico El Niño.

${ }^{3}$ Ocorrência do evento metereológico La Niña.

${ }^{4}$ Aplicação de $\mathrm{N}$ realizada 20 dias antes da dessecação da aveia preta.

${ }^{5}$ Incorporado ao solo em linhas distanciadas $45 \mathrm{~cm}$.

${ }^{6}$ Método proposto.

${ }^{7}$ Método usual.

${ }^{8} \mathrm{Na}$ entrelinha.

safra 2000/2001, ocorreu a produtividade mais elevada de milho, tendo havido diferenças significativas entre tratamentos, quanto ao método de aplicação de N, nas aplicações feitas em pré-semeadura, mas não em relação às épocas de aplicação de N. Em 2001/02, período com baixa precipitação pluvial, principalmente em janeiro e fevereiro de 2002, não foram observadas diferenças significativas entre os tratamentos quanto ao rendimento de grãos, exceto aquele com $\mathrm{N}$ aplicado a lanço em pré-semeadura (tratamento 3), tratamentos 7 e 11 e testemunha (tratamento 1). Os dados relativos a essa safra devem ser interpretados com ressalvas, por ter havido redução no potencial produtivo da cultura de milho, motivada pela distribuição irregular de chuvas (somente $55 \mathrm{~mm}$ no período de 15 dias antes e 15 dias após o pendoamento). No entanto, a tendência do efeito dos tratamentos foi semelhante à das demais safras. Assim, em anos de precipitação próxima ou inferior à normal, poder-se-ia aplicar N em pré-semeadura, confirmando resultados obtidos por BASSO \& CERETTA (2000). A dificuldade para implementar essa prática é prever qual a precipitação pluvial futura. Além disso, eventuais diferenças no desenvolvimento do milho, devido a aplicação de $\mathrm{N}$ em pré-semeadura, podem ter sido neutralizadas por eventos climáticos posteriores, como baixa precipitação pluvial no pendoamento do milho, em alguns anos do estudo. Deve ser considerado, ainda, que, em nenhum ano, o tratamento padrão ( $\mathrm{N}$ na semeadura + cobertura) apresentou produtividade significativamente inferior à dos tratamentos com $\mathrm{N}$ aplicado em pré-semeadura ou totalmente na semeadura, demonstrando a eficácia da atual recomendação de $\mathrm{N}$ para milho. Ainda, os tratamentos com $\mathrm{N}$ na semeadura + cobertura produziram, em média, cerca de $6 \%$ mais que aqueles 
Tabela 4 - Precipitação pluvial ocorrida durante os períodos de execução dos experimentos. Embrapa Trigo, Passo Fundo, RS

\begin{tabular}{|c|c|c|c|c|c|c|}
\hline Mês & $1997 / 98$ & 1998/99 & 1999/00 & $2000 / 01$ & $2001 / 02$ & Média de 30 anos \\
\hline & \multicolumn{6}{|c|}{$\mathrm{mm}$} \\
\hline Outubro & 550,4 & 118,9 & 177,1 & 339,3 & 275,5 & 167,1 \\
\hline Novembro & 339,9 & 68,5 & 118,6 & 164,2 & 116,5 & 141,4 \\
\hline Dezembro & 235,5 & 122,5 & 131,1 & 159,9 & 194,1 & 161,5 \\
\hline Janeiro & 231,0 & 125,3 & 143,6 & 212,5 & 96,0 & 143,4 \\
\hline Fevereiro & 357,6 & 114,4 & 105,7 & 196,5 & 76,7 & 148,3 \\
\hline Março & 229,9 & 65,5 & 267,4 & 110,5 & 356,8 & 121,3 \\
\hline Abril & 342,2 & 188,3 & 76,1 & 118,4 & 135,9 & 118,2 \\
\hline Total & 2286,5 & 803,4 & 1019,6 & 1301,3 & 1251,5 & 1001,2 \\
\hline
\end{tabular}

com aplicação em pré-semeadura, enquanto BORTOLINI et al. (2001) encontraram acréscimo de $14 \%$ no rendimento de grãos pela aplicação de $150 \mathrm{~kg}$ ha $^{-1}$ de $\mathrm{N}$ em cobertura em relação à aplicação feita em pré-semeadura. Além disso, o aumento da quantidade de $\mathrm{N}$ na semeadura além dos $30 \mathrm{~kg} \mathrm{ha}^{-1}$ recomendados (COMISSÃO...1995), também poderia gerar acréscimo de rendimento de grãos de milho (CERETTA et al., 2002), não havendo, portanto, vantagem com a aplicação de $\mathrm{N}$ em pré-semeadura.

Outras épocas de aplicação de $\mathrm{N}$ produziram resultados pouco promissores. $\mathrm{O}$ parcelamento da dose de $\mathrm{N}$ em três épocas (tratamento 9), embora tenha mostrado bons rendimentos de grãos, acarreta despesas adicionais para o agricultor. A aplicação de $\mathrm{N}$ cerca de 20 dias antes da dessecação da aveia preta (tratamento 2) não se mostrou viável, pois a aveia absorveu parte do $\mathrm{N}$ aplicado (dados não apresentados) e, segundo CERETTA et al. (2002), a substituição do N que seria aplicado em cobertura no milho pela aplicação no afilhamento da aveia preta reduziu o rendimento de grãos de milho, provavelmente porque ocorre pouca transferência de $\mathrm{N}$ contido nos resíduos culturais de aveia preta para o milho. Segundo DA ROS (1993), nos primeiros 30 dias de desenvolvimento de milho, apenas $34 \%$ do $\mathrm{N}$ presente em resíduos de aveia preta foi liberado para o solo.

\section{Métodos de aplicação de $\mathbf{N}$}

$\mathrm{Na}$ média dos cinco anos, o tratamento com incorporação de $\mathrm{N}$, na dose de $100 \mathrm{~kg} \mathrm{ha}^{-1}$, aplicado na forma de uréia, em pré-semeadura (tratamento 4), produziu 6,3\% mais que o tratamento com aplicação de $\mathrm{N}$ a lanço (tratamento 3). Contudo, a vantagem da incorporação de $\mathrm{N}$ mostrou-se bastante variável de ano para ano, resultando em ganho médio de $479 \mathrm{~kg} \mathrm{ha}^{-1}$ de grãos de milho. Para os tratamentos que receberam parte do $\mathrm{N}$ aplicado em pré-semeadura e parte na semeadura (tratamentos 5 e 6 ), a incorporação de $\mathrm{N}$ ao solo promoveu acréscimo no rendimento de grãos equivalente a 5,8\%. Já a incorporação de $70 \mathrm{~kg} \mathrm{ha}^{-1}$ de $\mathrm{N}$ na semeadura (tratamento 8) proporcionou incremento em rendimento de $4,6 \%$, na média dos anos 2000/2001 e 2001/2002, em relação à média do tratamento com $\mathrm{N}$ aplicado a lanço, na superfície do solo (tratamento 7). O benefício da incorporação de $\mathrm{N}$ aplicado em cobertura foi igualmente constatado (tratamento 12 vs 11), exceto na safra 1999/2000, onde o efeito da incorporação foi negativo. O acréscimo de rendimento devido à incorporação foi, em média, de $1,5 \%$, porém, se for desconsiderada a safra 1999/ 2000, o efeito favorável da incorporação de $\mathrm{N}$ foi de $3,9 \%$ para a aplicação em cobertura. Houve maior ganho em rendimento de grãos de milho, decorrente da incorporação de $\mathrm{N}$, quando as aplicações do fertilizante nitrogenado foram realizadas em présemeadura ou na semeadura (tratamentos 3 e 4, 5 e 6), em comparação com o $\mathrm{N}$ aplicado em cobertura (tratamentos 11 e 12). Provavelmente isso esteja relacionado ao fato de, na época de aplicação de $\mathrm{N}$ em cobertura, o milho apresenta elevada demanda de $\mathrm{N}$ por unidade de área. Já nos estádios iniciais de desenvolvimento da cultura a demanda é máxima por unidade de segmento de raiz. A razão da menor produtividade observada nos tratamentos com aplicação superficial de $\mathrm{N}$ deve-se provavelmente à volatilização de amônia, como verificado por LARA CABEZAS et al. (1997), em milho. Contudo, as perdas de $\mathrm{N}$ na forma de amônia são muito dependentes das condições de solo e de chuvas que sucedem à aplicação de uréia. BANDEL et al. (1980) observaram que perdas de amônia derivadas da uréia aplicada na superfície de solos são pouco previsíveis em condições de campo. Sugeriram, então, para milho cultivado em plantio direto, a incorporação da uréia ao solo.

Ciência Rural, v. 34, n.4, jul-ago, 2004. 


\section{CONCLUSÕES}

A aplicação de $\mathrm{N}$ na semeadura e em cobertura proporcionou rendimento de milho estatisticamente semelhante às aplicações efetuadas em pré-semeadura e na semeadura.

Em safra com elevada precipitação nos estádios iniciais de desenvolvimento do milho, a aplicação de $\mathrm{N}$ na semeadura e em cobertura ocasionou rendimento de milho superior à aplicação em présemeadura e na semeadura.

A incorporação do $\mathrm{N}$ ao solo aumentou o rendimento de milho em cerca de $5 \%$.

\section{REFERÊNCIAS BIBLIOGRÁFICAS}

BANDEL, V.A.; DZIENIA, S.; STANFORD, G. Comparison of $\mathrm{N}$ fertilizers for no-till corn. Agronomy Journal, Madison, v.72, n.2, p.337-341, 1980.

BASSO, C.J.; CERETTA, C.A. Manejo do nitrogênio no milho em sucessão a plantas de cobertura de solo, sob plantio direto. Revista Brasileira de Ciência do Solo, Campinas, v.24, n.4, p.905-915, 2000.

BORTOLINI, C.G. et. al. Rendimento de grãos de milho cultivado após aveia-preta em resposta a adubação nitrogenada e regime hídrico. Pesquisa Agropecuária Brasileira, Brasilia, v.36, n.9, p.1101-1106, 2001.

CERETTA, C.A. et al. Manejo da adubação nitrogenada na sucessão aveia preta/milho, no sistema plantio direto. Revista Brasileira de Ciência do Solo, v.26, n.1, p.163-171, 2002.

COMISSÃO DE FERTILIDADE DO SOLO - RS/SC. Recomendações de adubação e de calagem para os estados do Rio Grande do Sul e de Santa Catarina. 3.ed. Passo Fundo : SBCS - Núcleo Regional Sul, 1995. 223p.

DA ROS, C.O. Plantas de inverno para cobertura do solo e fornecimento de nitrogênio ao milho em plantio direto. 1993. 85p. Dissertação (Mestrado em Agronomia) - Programa de Pósgraduação em Agronomia, Universidade Federal de Santa Maria.

DA ROS, C.O. et al. Produtividade de milho com diferentes estratégias de adubação nitrogenada no sistema plantio direto. In: (SEMINÁRIO INTERINSTITUCIONAL DE ENSINO, PESQUISA E EXTENSÃO \& II MOSTRA DE INICIAÇÃO CIENTÍFICA), 4., 1999, Cruz Alta. Anais... Cruz Alta : UNICRUZ, 1999. CD-ROM.

EMBRAPA. Centro Nacional de Pesquisa de Solos (Rio de Janeiro, RJ). Sistema brasileiro de classificação de solos. Brasília : Embrapa Produção de Informação; Rio de Janeiro : Embrapa Solos, 1999. 412p.

ESCOSTEGUY, P.A.V.; RIZZARDI, M.A.; ARGENTA, G. Doses e épocas de aplicação de nitrogênio em cobertura na cultura do milho em duas épocas de semeadura. Revista Brasileira de Ciência do Solo, Campinas, v.21, n.1, p.71-77, 1997.

LARA CABEZAS, W.A.R. et al. Balanço da adubação nitrogenada sólida e fluida de cobertura na cultura de milho, em sistema plantio direto no triângulo mineiro (MG). Revista Brasileira de Ciência do Solo, Viçosa, v.24, n.2, p.363-376, 2000.

MUZILLI, O.; OLIVEIRA, E.L. Nutrição e adubação. In: FUNDAÇÃO INSTITUTO AGRONÔMICO DO PARANÁ (Londrina, PR). O milho no Paraná. Londrina, 1982. p.88104. (Circular, 29).

PAULETTI, V.; COSTA, L.C. Época de aplicação de nitrogênio no milho cultivado em sucessão à aveia preta no sistema plantio direto. Ciência Rural, Santa Maria, v.30, n.4, p.599-603, 2000.

SÁ, J.C. de MORAES. Manejo de nitrogênio na cultura do milho no sistema plantio direto. Passo Fundo, RS : Aldeia Norte, 1996. 23p.

SAS. SAS/STAT User's Guide. Version 6. Cary : SAS Institute, 1993. V.2, 1686p.

TORBERT, H.A. et al. Short-term excess water impact on corn yield and nitrogen recovery. Journal of Production Agriculture, Madison, v.6, n.3, p.337-344, 1993. 